\title{
El tratamiento de la interculturalidad desde la literatura juvenil: Algún día, cuando pueda llevarte a Varsovia
}

The treatment of the interculturality from the Juvenile literature: Algún día, cuando pueda llevarte a Varsovia

\author{
Paula Rivera Jurado \\ Departamento de Didáctica de la \\ Lengua y la Literatura. \\ Universidad de Cádiz \\ paula.rivera@uca.es
}

\section{Resumen}

En este trabajo se presenta una reflexión sobre el desarrollo de la competencia intercultural en el ámbito de la educación literaria a través de la lectura de la novela juvenil Algún día, cuando pueda llevarte a Varsovia, de Lorenzo Silva. Tras analizar, en general, las posibilidades de la literatura juvenil para el tratamiento intercultural y, en particular, las de la obra elegida, se ofrecen algunas propuestas didácticas para su dinamización en el aula.

\begin{abstract}
This paper presents a reflection on the development of intercultural competence in the field of literary education through reading young novel Algún día, cuando pueda llevarte a Varsovia, by Lorenzo Silva. After analyzing, in general, the chances of juvenile literature for intercultural treatment and, in particular, the work chosen, some educational proposals for revitalization in the classroom are offered.
\end{abstract}

Palabras clave: Educación literaria, Educación intercultural, literatura juvenil, Algún día, cuando pueda llevarte a Varsovia

Keywords: Literary education, intercultural education, Young literatura, Algún día, cuando pueda llevarte a Varsovia

\section{Introducción}

La educación literaria desde una perspectiva intercultural permite, en palabras de Ibarra y Ballester (2010, p. 12), trascender las estrechas fronteras de una única asignatura e instaurar un espacio de reflexión desde el que leer y habitar el mundo. Esta concepción de interculturalidad bajo el seno de una educación literaria interdisciplinar nos conduce a reflexionar sobre el valor didáctico de los textos literarios como mediadores entre los adolescentes y el conocimiento de otras culturas diferentes a la propia.

Bien es cierto que los textos literarios no son del todo bien acogidos por parte de los jóvenes de hoy día, sobre todo, si estos son presentados aún bajo un enfoque historicista y como materia de estudio secuenciada cronológicamente en épocas. Por suerte, la 
enseñanza de la literatura en los últimos años se ha abierto a un extenso abanico de posibilidades metodológicas que permiten múltiples estrategias para el aprovechamiento didáctico de los textos y el logro de la competencia literaria; en nuestro caso, desde una visión intercultural y, sin olvidar, como señalan Ballester e Ibarra (2009,p. 31) "la motivación, el juicio de valor y el placer de los estudiantes, puesto que, en última instancia, la competencia literaria se adquiere a partir de la inmersión y de la interpretación del texto".

¿Cómo lograr, pues, el desarrollo de una competencia literaria intercultural desde el disfrute de la lectura? Partiendo, por un lado, de la idea de Mendoza (2005, p. 41) de que la literatura infantil y juvenil (en adelante, LIJ) es la base para el desarrollo de la educación literaria y, por otro lado más recientemente, de los planteamientos teóricos de los autores anteriores (2015) para quienes la LIJ constituye un elemento básico en la formación de los individuos como lectores, así como en la creación y desarrollo de su competencia literaria, ofrecemos en este trabajo algunas orientaciones didácticas para el tratamiento de la educación intercultural a partir de la lectura de la novela juvenil Algún día, cuando pueda llevarte a Varsovia, de Lorenzo Silva.

\section{El tratamiento de la interculturalidad desde la literatura juvenil}

Según datos de Ramírez (2003, p. 64) la presencia de ciudadanos polacos en España data ya desde los años sesenta, pero es hacia finales de la década de los ochenta y, sobre todo, en los noventa cuando, a partir de la apertura de sus fronteras comienzan a verse en España de una forma significativa. La llegada y la acogida de población inmigrante es uno de los temas que desde los años noventa hasta nuestros días ha sido centro de interés de numerosos títulos de obras de literatura infantil y juvenil; sin embargo, el colectivo polaco no ha ocupado en estas obras lugares de protagonismo. Tal vez por encontrarles menos lejanos culturalmente que a otros o por no unir a España y a Polonia ninguna historia de agravios comparativos (2003, p. 83). Otros grupos que sí han tenido un gran espacio en el panorama de la LIJ han sido los inmigrantes africanos; así, para Sanz (1999, p. 145) hablar de interculturalidad es, casi, sinónimo de hablar de África. De hecho, pensemos en lecturas tan conocidas como Abdel (1994), La aventura de Saíd (1996) o África en el corazón (2004).

Este reflejo que han tenido los cambios sociales en la literatura para jóvenes requiere de una revisión sobre la manera de acceder a este tipo de textos y su proyección desde las aulas. Superado el debate sobre los valores estéticos-literarios de las obras de literatura juvenil conviene repasar la utilidad didáctica de este género para el desarrollo de aquellas posturas que tienen que ver con la interculturalidad.

Según Moreno (2006, p. 20) se entiende por literatura juvenil:

un conjunto de manifestaciones literarias en diversos soportes que resulta recomendable en la formación del receptor adolescente o joven, que suele ser emitida por adultos y que generalmente están dirigidas intencionadamente a receptores que están en la adolescencia o en la primera juventud, y puede ser simultaneada con la lectura de obras de la literatura infantil o de la literatura "general", según el momento del lector.

Es justamente esta especificidad receptora una de las características que hacen de este 
género idóneo para destinarlo al tratamiento de la educación intercultural. A este respecto, de acuerdo con la idea de Ballester (2015, pp. 169-170):

\begin{abstract}
a partir de la Literatura Infantil y Juvenil, aquella destinada de manera específica al niño y al joven en tanto receptores privilegiados de ésta en los diferentes niveles educativos, podemos aproximar al alumnado a la realidad en la que se encuentra inmerso y desde ésta analizar los principales núcleos de debate en torno a la interculturalidad con la finalidad de la formación de posturas críticas en torno a actitudes discriminatorias como el racismo, la xenofobia o cualquier perpetuación de estereotipos de raza o etnia.
\end{abstract}

Igualmente, otras características distintivas del género como la frecuencia de protagonistas jóvenes en las mismas edades que los lectores, las acciones grupales y ambientes juveniles (Cerrillo, 2015: 5-6) hacen que esta aproximación a la realidad que les rodea se les asemeje más cercana y la reflexión crítica se torne más próxima desde la identificación con el otro.

En segundo lugar, tal y como señalan Romero, Jiménez y Trigo (2015, p. 116) los textos juveniles, al poseer estructuras lingüísticas cercanas a los adolescentes, posibilitan la madurez lectora y facilitan el fomento de la lectura desde el punto de vista del disfrute. Esta singularidad lingüística del género juvenil hace que, igualmente, propicie el encuentro con el personaje desde la empatía dado que, en la mayor parte de los casos, este protagonista se presenta desde una voz narrativa en primera persona lo que favorece la capacidad de sentir y compartir las vicisitudes del otro como propias.

En tercer lugar, aunque la función de la LIJ no es necesariamente la de servir de vía secundaria de acceso a la gran literatura (Mendoza, 2001, p. 147); lo cierto es que en determinados momentos debe entenderse como una pieza clave desde la que ir desarrollando el intertexto intercultural del joven para el reconocimiento de estos rasgos en producciones literarias más complejas. En este sentido, al acercar a los alumnos a los grandes temas, valores e inquietudes de la humanidad (la injusticia, la amistad, el rechazo, la solidaridad...), conseguirá una auténtica educación en valores. (Bastida, Bordons y Rins, 2005, p. 83).

En resumen:

Características LIJ Utilidad didáctica para el desarrollo de la

Interculturalidad

Dirigidas a un receptor Formación de posturas críticas desde la determinado

identificación con el otro niño/joven.

Poseen un lenguaje cercano al adolescente

Desarrollo de actitudes de empatía hacia el otro

desde el empleo de un lenguaje próximo. 
Sirven de vía de acceso a la gran literatura
Reconocimiento de marcas interculturales desde el establecimiento de relaciones intertextuales.

\title{
Algún día, cuando pueda llevarte a Varsovia
}

Algún día, cuando pueda llevarte a Varsovia (1997), junto con El cazador del desierto (1998) y La lluvia de París (2000) conforman la "trilogía de Getafe", iniciada por Lorenzo Silva para jóvenes y continuada, según su propia confesión, con las conversaciones y temas surgidos en su relación con los lectores (Moreno, 2006, p. 19).

Estas tres novelas presentan algunas características que permiten ubicarlas, en opinión de Fornieles y Urán (2005) de forma más o menos precisa dentro de la literatura juvenil. Así, se recogen, en base a los criterios de estos autores, cuáles de estos rasgos pueden sitúan a Algún día... en el género de la novela para jóvenes:

\section{a) Realismo}

\begin{abstract}
Aunque incluyan algunas peripecias poco comunes, según ambos autores, "las novelas de Silva se mueven siempre en un marco verosímil, que se corresponde con las formas de vida más extendidas entre los posibles lectores. La protagonista de Algún día..., Laura -soporte narrativo de la historia-, vive en Getafe, estudia en un instituto, se queja de sus padres, discute con su hermano, se siente atraída por los chicos...". En definitiva, se convierte en un personaje fácilmente identificable con el lector.
\end{abstract}

\section{b) Fantasía}

"Para captar el interés del lector al que van dirigidas, Silva mezcla con acierto determinadas dosis de aventura -el secuestro imaginado de un barco en Algún día...- con la realidad más inmediata - la convivencia entre adolescentes en un barrio de clase media de Getafe- y, de este modo, se esfuerza por conseguir que el lector menos experimentado supere las dificultades que tal vez ofrezca la lectura".

\section{c) Valores}

Por último, para estos autores "la amenidad, en esta obra, no supone renunciar a promover en el lector una ética. Al contrario. El realismo implica en este caso recoger determinados valores; y es que los adolescentes ideados por Silva -recreados bajo una forma de vivir que se circunscribe a los hábitos comunes de la clase media- reconocen también - a través del encuentro con el otroque les ha tocado vivir en un mundo privilegiado y que su conducta no puede estar gobernada sólo por la queja".

Por otro lado, siguiendo las condiciones básicas en las que según García (2006, p. 94) se debe desarrollar el tratamiento de la realidad intercultural -la aceptación del pluralismo y la tolerancia; la visión y la valoración histórica de lo propio; el desmontar prejuicios y el combate a la ignorancia y a los estereotipos- puede considerarse que la obra elegida cumple con estos cuatro requisitos y se muestra idónea para la formación de valores interculturales entre los adolescentes. A modo de justificación, se ilustran cada una de 
estas condiciones para el tratamiento de la interculturalidad desde la selección de fragmentos representativos de la lectura:

Condiciones Justificación desde la obra

La aceptación del pluralismo y la tolerancia

La visión y la valoración histórica de lo propio (y lo ajeno)

\section{El desmontar prejuicios}

El combate a la ignorancia y a los estereotipos
"Otra cosa que me costaba entender era cómo a todo el mundo le molestaba que vinieran a vivir al portal los polacos, cuando eran la gente más guapa y perfecta que yo había visto en mi vida, tanto o más que la que sale en las películas americanas, donde todas son como cualquier chica de aquí querría ser, aunque personalmente me reviente reconocerlo (p. 14)".

"La historia de mi país es un buen ejemplo, porque mi país ha conocido esa forma de perder muchas veces. A Polonia la han invadido casi todos los países que la rodean. Los rusos, los alemanes y a veces los dos al mismo tiempo. Rusia y Alemania son países mucho más grandes que Polonia, y Polonia nunca podría invadirlos. Después de cada derrota, todo lo que podía hacer era tratar de reconstruirse ella, no intentar invadir Rusia o Alemania, que habría sido imposible y la forma de no dejar de perderse nunca (p. 79)".

"Aquel chico ya no era para mí un desconocido, sino alguien que me había enseñado durante horas y horas su corazón (pp. 181-182)".

"Mi padre me aconsejó que no me encariñara mucho con quien está de paso, porque quien está de paso se acaba yendo siempre (p. 188)".

Para el autor, son estos los valores que muchos de los que se ocupan por el estudio, la promoción y la difusión de la LIJ han señalado como sus grandes posibilidades educativas. Por ello, como consejo a educadores, avisa: "los que participamos de estas ideas debemos plantearnos cómo aprovechar el acceso de nuestros alumnos a esas creaciones literarias dentro del contexto de una educación intercultural” (p. 94). 


\section{Sugerencias didácticas para el tratamiento intercultural de la lectura}

A continuación se proponen una serie de actividades para el desarrollo de la competencia intercultural y el conocimiento del otro a partir de la comparación entre lo propio y lo ajeno. Según este objetivo general, las actividades se han distribuido en tres apartados con sus respectivos objetivos específicos: el primero, actividades desde la investigación; el segundo, actividades desde el debate y, el tercero, actividades desde la reflexión. En último lugar, se incluye una escala de evaluación a modo de seguimiento y control de la propuesta a fin de conocer el logro de cada uno de los objetivos marcados.

\section{a) Actividades desde la investigación}

Para Kunz (2002, p. 171) el didactismo de esta novela reside en que no informa realmente sobre Polonia y los emigrantes polacos, "sino que brinda a los lectores unos datos mínimos para invitarlos a leer más sobre el tema en otros libros, como lo hará también la narradora".

Objetivos específicos:

- Recabar información sobre los símbolos polacos más conocidos que aparecen en la novela.

- Comparar estos símbolos con los propios del lugar de origen del alumno.

a. 1.) Ubicación en el mapa y accidentes geográficos

Lee el siguiente fragmento extraído del capítulo 2 (p. 23):

"Si cogéis también vosotros un atlas veréis que Polonia limita ahora con Lituania, Bielorrusia, Ucrania, Eslovaquia, la República Checa y al oeste, como siempre, Alemania. También veréis las ciudades más importantes, que tienen todas nombres más o menos fáciles en español y dificilísimos en polaco, aunque para ver eso tendréis que tener un atlas bilingüe, como el mío. En español se llaman: Danzig, Stettin, Breslau, Cracovia, Varsovia. Y en polaco: Gdańsk, Szczecin, Wrocław, Kraków, Warszawa. Otras se llaman sólo de una manera: Poznań, Katowice, Łódź, Lublin”.

$\Rightarrow$ ¿Qué debes hacer? Completa el mapa con los países que rodean a Polonia y con las ciudades más importantes que Laura señala. Puedes ayudarte de Internet o, como avisa la protagonista, de un atlas.

Lee el siguiente fragmento extraído del capítulo 6 (p. 68):

"Otra vez el dato oportuno, pensé, y la palabra exacta: un río navegable. ¿Se la había enseñado el marinero de Cádiz? Sin embargo, me fijé más en esa otra palabra, una nueva palabra encantada que yo no había oído antes: Vístula, así había llamado al río, también a la manera española. Luego averigüé que ellos lo decían de otra forma, Wisła, que suena aproximadamente Wisua, pero para mí sería siempre así, Vístula, que fue como sonó por primera vez en mi corazón”.

$\Rightarrow$ ¿Qué debes hacer? Señala en el mapa el recorrido del río Vístula por Polonia. Igualmente, puedes investigar a través de Internet o, como apunta Laura, de un atlas. 
Lee el siguiente fragmento extraído del capítulo 2 (p. 24):

"También sabía que allí había nacido Chopin, que aunque todos digan su nombre en francés es un músico polaco que se da en Primero. Este Chopin compuso un concierto para piano y orquesta, que se llama Concierto número 1 y que en el examen final hay que ser capaz de distinguirlo de la Sinfonía pastoral de Beethoven, la Sinfonía fantástica de Berlioz (este no se dice en francés, aunque sí era francés) y los Conciertos de Brandemburgo de Bach (que se dice Baj, algo así como si fuera hindú)".

$\Rightarrow$ ¿Qué debes hacer? Pon en común con tus compañeros qué personajes célebres polacos conocéis y en qué ámbito cultural han destacado.

\section{a. 3.) Otros}

\section{- Símbolos bélico-históricos}

\section{Lee el siguiente fragmento extraído del capítulo 2 (pp. 22-23):}

"Mi profesor de Sociales nos contó además una anécdota muy impresionante. Resulta que, cuando los polacos ya habían perdido todas las posibilidades de resistir, una división de caballería que se llamaba Pomorska cargó a la desesperada contra los tanques alemanes. Murieron todos, desde luego, sin romper un solo tanque con sus espadas y sus lanzas. Desde que me lo contaron, cuando me acuerdo de la división Pomorska siento una especie de escalofrío, y me pregunto qué clase de cosa te tienen que meter en la cabeza para cargar a caballo contra una división acorazada, y en qué pensarían aquellos jinetes".

$\Rightarrow$ ¿Qué debes hacer? Pregúntale a tu profesor de Sociales acerca del papel que jugó Polonia en la II Guerra Mundial.

- Símbolos religiosos

Lee el siguiente fragmento extraído del capítulo 2 (p. 24):

“¿Qué más sabía de Polonia? Hice un repaso rápido. Sabía, claro, que el papa era polaco y que iba allí mucho y todos debían ser muy católicos, para haber dado un papa. De hecho tenían una virgen de color negro muy famosa que no sabía cómo se llamaba (ahora sí lo sé, y es un nombre polaco de los difíciles de veras, se llama la virgen de Czestochowa)".

$\Rightarrow$ ¿Qué debes hacer? Averigua quién era el papa polaco del que habla Laura; además, busca la imagen de la virgen a la que Laura hace referencia e intenta averiguar la explicación a los dos rasguños sobre la derecha del rostro.

\section{a. 4.) Conexiones intertextuales}

La intertextualidad cumple en la novela una función didáctica (Kunz, 2002, pp. 179180):

“despertar la curiosidad de lectores y lectoras juveniles por algunas de las obras literarias que probablemente no forman parte de las preferencias de su generación, e invitarlos a leer estos libros sintiendo la actualidad que pueden adquirir para ellos las novelas Tarás Bulba de Gógol y The Shadow Line de Joseph Conrad".

Lee el siguiente fragmento extraído del capítulo 7 (p. 76): 
"Andrés estaba sentado encima de la cama. Llevaba un chándal azul y tenía un libro en las manos. Cuando yo entré en su cuarto, lo cerró y lo dejó encima de la mesilla. Estaba en español y pude leer el título y el nombre de autor en el lomo: era un libro de Joseph Conrad y se llamaba La línea de sombra. Le dediqué tanta atención al libro porque al principio me costaba dedicársela a Andrés".

$\Rightarrow$ ¿Qué debes hacer? Averigua quién era Joseph Conrad y cuál era su nacionalidad.

$\Rightarrow$ Averigua a qué otra obra de Joseph Conrad pertenece el siguiente fragmento:

"La mente del hombre es capaz de cualquier cosa, porque está todo en ella, tanto el pasado como el futuro. ¿Qué había allí, después de todo? Júbilo, temor, pesar, devoción, valor, ira -¿cómo saberlo?-, pero había una verdad, la verdad despojada de su manto del tiempo. Que el necio se asombre y se estremezca; el hombre sabe y puede mirar sin parpadear".

[D] Lee el siguiente fragmento extraído del capítulo 8 (p. 94):

“-Has leído Tarás Bulba? -le pregunté a Andrés, sin poder contenerme-. -¿Qué?

-Tarás Bulba. Es la historia de un cosaco ruso, bueno, ucraniano, pero cuando Ucrania era de Rusia, que lucha contra los polacos.

- No lo he leído. Pero debe de haber muchas historias de esas. Ya te conté que los rusos siempre han estado luchando contra los polacos. ¿Es un libro ruso?

-Sí.

-Entonces seguro que el cosaco gana".

$\Rightarrow$ ¿Qué debes hacer? Averigua quiénes eran los cosacos para entender por qué Andrés afirma "seguro que el cosaco gana".

\section{b) Actividades desde el debate}

La pedagogía intercultural de la literatura se educa ante todo en la oralidad, donde se propician coloquios y debates heurísticos. El profesor debe aquí aprender a preguntar para llevar al alumno a reflexionar, e intentar razonar sus respuestas y conclusiones. Este sistema también educa en valores pues enseña al alumno a respetar la palabra y las ideas de los otros, aunque no coincidan con las suyas (González y Caro, 2009).

\section{Objetivos específicos:}

- Intercambiar posturas y opiniones.

- Generar el respeto y la aceptación a puntos de vista diversos desde la dinámica del debate. 
Lee la siguiente noticia extraída fragmento extraída de www.antena3.com:

\section{SOLIDARIDAD | UNA ESCUELA DE ENTRENADORES LE DARÁ CASA Y MANUTENCIÓN}

\section{El refugiado sirio que sufrió la zancadilla de una periodista será acogido en Getafe}

Son Osama Abdul Mohsen y su hijo de siete años fueron víctimas de la zancadilla de la periodista húngara Petra Lászlo cuando intentaban cruzar la frontera entre Serbia y Hungría. Su imagen cayendo al suelo mientras eran increpados por las autoridades conmovió a una escuela de entrenadores de Getafe (Madrid) que descubrieron que Son Osama era un reputado entrenador en su país. La escuela deportiva acogerá al sirio y a su hijo, que llegan esta misma noche a Madrid, e iniciará los trámites legales para que pueda establecerse como entrenador en su centro.

Imagen 1. Noticia para la reflexión desde la actualidad inmediata del alumno.

Fuente http://cort.as/qROW

Cuestiones para el debate intercultural:

$\Rightarrow$ Activación de conocimientos previos: ¿qué conocéis sobre la guerra de Siria? ¿Qué conocéis sobre los refugiados que están viniendo a Europa?

$\Rightarrow$ Comprensión de la noticia: ¿Qué les ocurrió a Son Osama Abdul Mohsen y a su hijo de siete años cuando intentaban cruzar la frontera entre Serbia y Hungría? ¿Por qué creéis que este suceso ha dado la vuelta al mundo? ¿Cómo ha decidido actuar la escuela deportiva al respecto?

$\Rightarrow$ Contraste entre la noticia y la obra: ¿qué similitudes encontráis entre la actitud de la escuela de entrenadores de Getafe hacia Son Osama Abdul Mohsen y la de Laura respecto a Andrej?

c) Actividades desde la reflexión

Objetivo específico:

- Forjar el pensamiento crítico en el alumno desde la reflexión intercultural.

Volved a leer y reflexionad sobre los siguientes fragmentos de la obra:

$\Rightarrow$ Valoraciones negativas. ¿Qué opinión os merecen las afirmaciones de Roberto y de la vecina de Laura?

"Los polacos son ex comunistas, y eso es casi tan malo como ser negro" (Roberto, p. 13).

"Lo malo es que nunca vienen solos. Verás como se les ocurra llamar a todos los de su familia, y nos encontremos con catorce o quince polacos metidos en el piso, durmiendo en colchonetas y viviendo como puercos" (Cristina, vecina del $\left.5^{\circ} \mathrm{A}, \mathrm{p} .17\right)$.

$\Rightarrow$ Valoraciones intermedias. ¿Qué opinión os merece la siguiente recomendación que le hace el padre de Laura a su hija?

"Son buena gente y tienen todo el derecho de estar aquí y ganarse la vida. El caso es que, aunque no sean mala gente, quizá deberías tratar de ir con otros chicos" (padre de Laura, pp. 82-83). 
$\Rightarrow$ Valoraciones positivas. ¿Qué opinión os merece la atracción que expresa Laura ante lo desconocido?

"No deja de ser curioso que las palabras con que Andrés me iba atrayendo a su tierra fueran palabras españolas. A mí me transportaba a Polonia, y a Polonia la traducía siempre al español” (p.e. río Vístula: Wista) (Laura, pp. 68-69).

\section{d) Escala de evaluación}

Como todo proceso didáctico exige, incluimos una escala de evaluación en la que quedan recogidos los objetivos planteados para cada tipología de actividad así como los descriptores de evaluación que ayudan a delimitar qué habilidades son necesarias para la consecución de cada objetivo. Asimismo, estos descriptores se acompañan de una escala de valoración que comprende del 1(poco) al 4 (bastante) y que va a precisar el grado de consecución de cada habilidad y, a su vez, de los objetivos marcados.

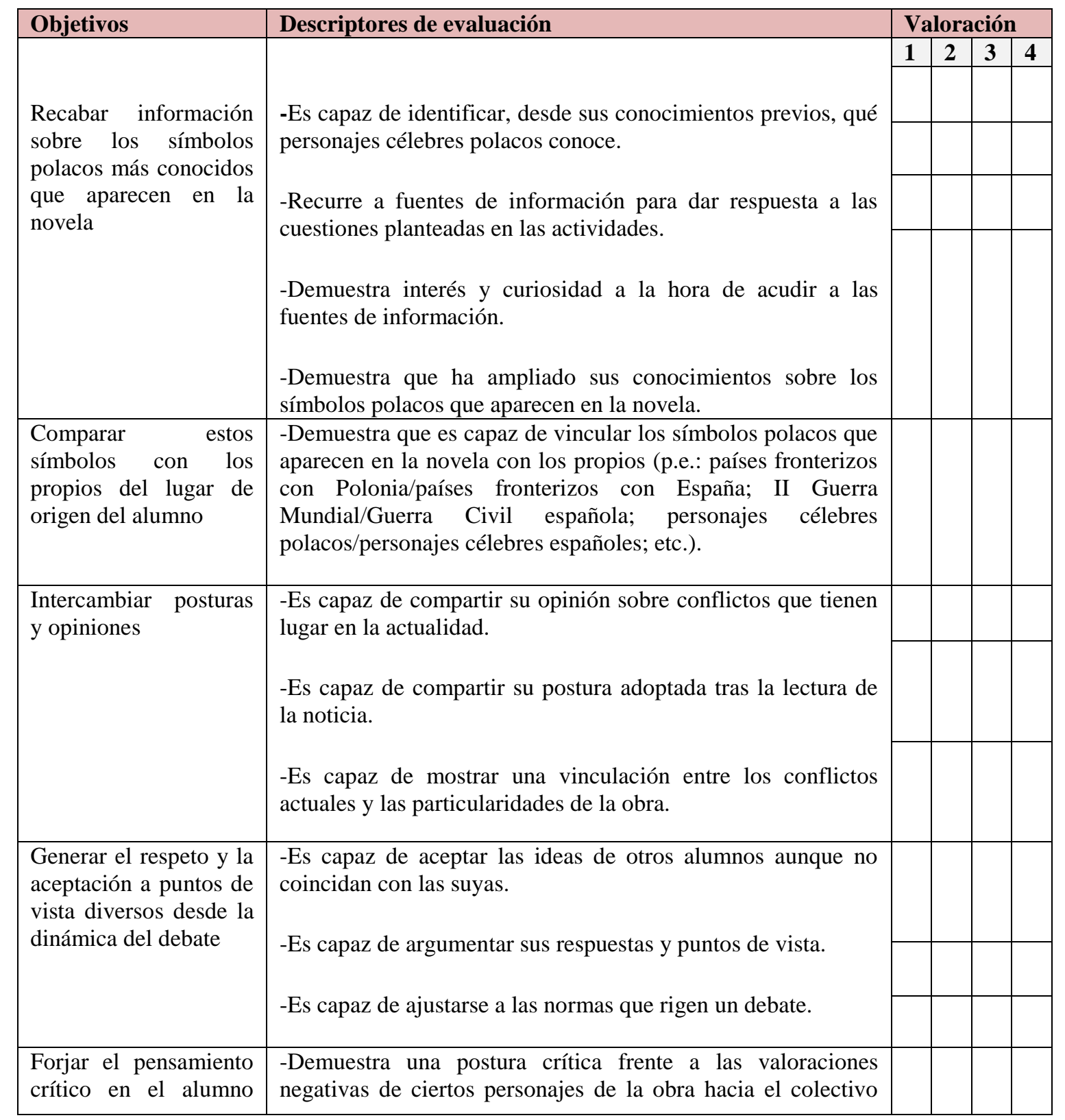




\begin{tabular}{|l|l|l|l|l|}
\hline $\begin{array}{l}\text { desde la reflexión } \\
\text { intercultural }\end{array}$ & polaco. & & & \\
& $\begin{array}{l}\text {-Es capaz de ofrecer una valoración crítica a las posturas } \\
\text { intermedias adoptadas por ciertos personajes de la obra hacia } \\
\text { los polacos. }\end{array}$ & & & \\
\cline { 2 - 6 } & $\begin{array}{l}\text {-Es capaz de valorar críticamente las posturas positivas de } \\
\text { determinados personajes de la obra hacia la cultura polaca. }\end{array}$ & & & \\
\cline { 1 - 5 } &
\end{tabular}

Figura 1. Escala de evaluación de la propuesta didáctica.

\section{Conclusiones}

El logro de una competencia literaria intercultural desde el disfrute, como planteábamos al comienzo del trabajo, implica la mediación del docente desde dos vías de actuación que consideramos esenciales: por un lado, desde la atención a la prescripción curricular $\mathrm{y}$, por otro, desde una adecuada selección de lecturas de aula. Si atendemos a lo establecido por el currículum, observamos que la didáctica de la literatura se orienta hacia el hacer de la lectura fuente de placer, de enriquecimiento personal y de conocimiento del mundo y de otras culturas. En segundo lugar, una adecuada selección de lecturas de LIJ escogidas por su utilidad intercultural, no por mediaciones editoriales, puede contribuir a lograr el objetivo que hemos señalado al comienzo.

Este es el caso Algún día, cuando pueda llevarte a Varsovia, una lectura aconsejable para ser incluida en cualquier plan lector que se desarrolle en la educación secundaria con el deseo de fomentar el conocimiento de otras culturas entre los jóvenes. La elección de esta obra implica, además, huir de la recurrente figura del emigrante africano que comúnmente se encuentra en lecturas sobre inmigración que quizá pueda llegar a aburrir al lector habituado a encontrar este personaje estereotipo. Por el contrario, encontramos muy novedoso el acercarnos a la población polaca y, por extensión, del este, desde una novela juvenil.

A modo de reflexión final:

Todo educador consciente sabe hoy la importancia que la literatura infantil y juvenil tiene, no solo a la hora de desarrollar la capacidad recreativa, creadora, de expresión, imaginativa, etc., sino también en la adquisición de actitudes y valores, de conocimiento del mundo, de capacidad crítica y estética, de toma de conciencia y, en último término, en la toma de opciones. Esta realidad nos pone de manifiesto que no existe, ni es posible, una literatura neutral, por lo cual ningún educador puede dejar a merced del azar cuáles debieran ser las lecturas de niños y jóvenes. (Judson, 2000, p. 137).

\section{Referencias Bibliográficas}

Bastida, A.; Bordons, G. y Rins, S. (2005). Hacer reflexionar sobre los conflictos del mundo a partir de la literatura. En G. Bordons y A. Díaz-Plaja (coords.), Enseñar literatura en secundaria. La formación de lectores críticos, motivados y cultos (pp. 81-106). Barcelona: Graó. 
Cerrillo, P. (2015). Sobre la literatura juvenil. Verba hispanica: anuario del Departamento de la Lengua y Literatura Españolas de la Facultad de Filosofía y Letras de la Universidad de Ljubljana. 23, 211-228

Fornieles, J y Urán, I. (2005). El lugar de Lorenzo Silva en la literatura juvenil: Entrevista a Lorenzo Silva. Tonos digital: Revista electrónica de estudios filológicos, 9. Disponible en: https://goo.gl/2NMuuO (Consultado el 1/4/2016).

García, J. (2006). Literatura infantil e interculturalidad. En P. Cerrillo (ed.), La motivación a la lectura a través de la literatura infantil (pp. 89-110). Madrid: MEC.

González, M. y Caro, M. T. (2009). Didáctica de la literatura. La educación literaria. Disponible en: https://goo.gl/Sk7H3F (Consultado el 1/4/2016).

Ballester, J. e Ibarra, N. (2009). La enseñanza de la literatura y el pluralismo metodológico. Ocnos, 5, 25-36.

Ballester, J. e Ibarra, N. (2015). La función lectora y literaria en contextos multiculturales. Una perspectiva educativa e inclusiva. Teoría de la educación., 27, 161-183.

- (2010). La educación literaria e intercultural en la construcción de la ciudadanía. Aula de innovación educativa, 197, 9-12.

Judson, E. (ed.) (2000). Aprendiendo a resolver conflictos en la infancia. Madrid: Catarata.

Kunz, M. (2002). La Polonia de Getafe: Algún día cuando pueda llevarte a Varsovia, de Lorenzo Silva. En I. Andrés-Suárez, M. Kunz e I. D’ors, La inmigración en la literatura española contemporánea (pp. 165-184). Madrid: Editorial Verbum.

Mendoza, A. (2001). El intertexto lector: el espacio de encuentro de las aportaciones del texto con las del lector. Cuenca: Ediciones de la Universidad de Castilla-La Mancha.

- (2005). La educación literaria desde la LIJ. En M. C. Utanda, P. Cerrillo, y J. García (coords.), Literatura infantil y educación literaria (pp. 33-61). Cuenca: Ediciones de la Universidad de Castilla La-Mancha.

Moreno, A. (2006). Identidad y límites de la literatura juvenil. En M. V. Sotomayor (ed.), Personajes y temáticas en la literatura juvenil (pp. 9-28). Madrid: MEC.

Ramírez, E. (2003). La comunidad polaca en España: un colectivo particular. Reis: revista española de investigaciones sociológicas, 102, 63-92.

Romero M.F., Jiménez, R. y Trigo, E. (2015). Hojear la historia desde la educación literaria: un itinerario formativo para el joven lector. En R. Jiménez y M. F. Romero, Nuevas líneas de investigación e innovación en educación literaria (pp. 109-119). Barcelona: Octaedro.

Sanz, C. (1999). La interculturalidad en los textos para niños y jóvenes. Una literatura española para las aulas del siglo XXI. En Actas del XXXIV Congreso de la AEPE (pp.135-148). Zaragoza: AEPE. 